\title{
Ambalaj Atıklarının Çevresel Etkilerinin Yaşam Döngüsü Analizi İle Belirlenmesi: Mühendislik Fakültesi Örneği
}

\author{
Serpil Güneralp ${ }^{1}$, Aliye Suna Erses Yay ${ }^{2 *}$ \\ ${ }^{1}$ Çevre Mühendisliği Bölümü, Mühendislik Fakültesi, Sakarya Üniversitesi Serdivan-Sakarya/Türkiye \\ ${ }^{2}$ Çevre Mühendisliği Bölümü, Mühendislik Fakültesi, Sakarya Üniversitesi Serdivan-Sakarya/Türkiye
}

03.05.2019 Geliş/Received, 15.11.2019 Kabul/Accepted

$\ddot{O} \mathbf{z}$

Bu çalışmanın ana amacı üniversite kampüslerinde oluşan ambalaj atıklarının yaşam döngüsü analizi ile çevresel etkilerinin belirlenmesidir. 2017 yılında Sakarya Üniversitesi Mühendislik Fakültesinde toplanan ambalaj atıkları çalışmanın fonksiyonel birimi olarak seçilmiş olup, bu kapsamda öncelikle mühendislik fakültesinde oluşan ambalaj atığı çeşitleri ve miktarları belirlenmiştir. Yaşam döngüsü analizi için Simapro 8.4 programı ve CML-IA etki kategorisi kullanılmıştır. Bu yöntemin etki grupları abiyotik tükenme, abiyotik tükenme (fosil yakıtlar), küresel 1sınma, ozon tabakası tahribatı, insan toksisitesi, tatlı su ekotoksisitesi, deniz ekotoksisitesi, karasal ekotoksisite, fotokimyasal oksidasyon, asidifikasyon ve ötrofikasyondur. Sistem sınırları karışık ambalaj atıklarının toplanması, taşınması, atık ayırma ve geri dönüşüm tesisinde ayrılması, kâğıt-kartonun preslenip, metal ve camın preslenmeden geri dönüşüm firmalarına satılması, plastik atıkların kırılıp, granül haline getirildikten sonra plastik üreticilerine satılması, geri kalan artıkların ve geri dönüştürülemeyen malzemelerin yakma tesisinde bertarafını içermektedir. Bu çalışmada ambalaj atığı yönetimi için 2 alternatif senaryo uygulanmış olup, ilk senaryoda ambalaj atıkları geri dönüştürülürken, 2. senaryoda düzenli depolamaya bertaraf için gönderilmiştir. Sonuçlara baktığımızda, ambalaj atıklarının geri dönüşümü çevresel etkileri azaltırken, depolanması deniz ekotoksisitesi, insan toksisitesi, tatlı su ekotoksisitesi ve fosil yakıtların abiyotik tüketiminde olumsuz etkiler göstermiştir.

Anahtar Kelimeler: üniversite, entegre atık yönetimi yönetimi, ambalaj atıkları, yaşam döngüsü analizi (YDA)

\section{Determination of Environmental Effects of Packaging Wastes by Life Cycle Analysis: A Case Study of An Engineering Faculty}

\begin{abstract}
The aim of this study is to determine the environmental impacts of packaging wastes in universities by life cycle analysis. The functional unit of the study was selected as the packaging wastes collected in the Engineering Faculty of Sakarya University in 2017. In this context, the packaging waste types and amounts which were formed in the engineering faculty were determined. SimaPro 8.4 software program and CML-IA effect category were used for life cycle analysis. The effect groups of the method are abiotic depletion, abiotic depletion

*Sorumlu Yazar (Corresponding Author): Aliye Suna Erses Yay

(e-posta: erses@ sakarya.edu.tr)
\end{abstract}


(fossil fuels), global warming, ozone depletion, human toxicity, freshwater aquatic ecotoxicity, marine aquatic ecotoxicity, terrestrial ecotoxicity, photochemical oxidation, acidification and eutrophication. System boundaries include collection of mixed packaging waste, transportation, separation of the mixed packaging in the sorting and recycling plant, selling pressed papers, cardboards, unpressed metals and glasses to the relevant companies, recycling of plastics into granulated form and its sale to plastic producers, and disposal of residual waste or non-recyclable materials by incineration. In the study, 2 alternative scenarios were modeled for packaging waste management. One of them is recycling and the other is landfilling of the packaging waste collected in the engineering faculty. Finally, the results indicated that recycling of packaging materials reduce the negative environmental impacts and landfilling of packaging waste indicates higher negative impacts on the marine aquatic ecotoxicity, human toxicity, freshwater aquatic ecotoxicity and abiotic depletion (fossil fuels).

Keywords: university, integrated waste management, packaging waste, life cycle assesment (LCA)

\section{Giriş}

Üniversitelerdeki öğrenci ve personel sayıları göz önüne alındığında kampüs içerisindeki yaşamı küçük bir şehir veya kasaba olarak değerlendirmek mümkündür. Üniversite kampüslerinde yüksek miktarlarda kâğıt, karton, plastik, cam, metal gibi geri dönüştürülebilir atıklar ortaya çıkmaktadır. Doğal kaynakların korunması ve ekonomik sebeplerden dolayı düzenli depo sahasına gidecek olan bu tür atık miktarı azaltılmalıdır. Azaltma için ise ambalaj atıkları yönetmeliğine göre diğer atıklardan ayrı olarak biriktirilmesi ve toplanması gerekmekte olup etkili bir yönetim sistemine, stratejisine veya planına ihtiyaç duyulmaktadır (Anonim, 2017). Başarılı bir entegre atık yönetimi planının üniversitelere adapte edilmesi ve uygulanması, atıkların çevresel etkilerinin azaltılması ve kaynakların daha verimli kullanılması açısından önemlidir. Hem dünya hem de ülkemizdeki üniversiteler atıklarının çeşitlerini ve miktarını belirleyip, yönetim planlarını hızla çıkarmaya başlamışlardır. Çevre ve Şehircilik Bakanlığı bu konuda Sıfır Atık Projesini başlatmış olup, Ege Üniversitesini pilot üniversite olarak seçmiştir (Anonim, 2019 a). Ülke genelinde üniversiteleri incelediğimizde Boğaziçi Üniversitesi, İstanbul Teknik Üniversitesi (ITTÜ), Ege Üniversitesi, Ortadoğu Teknik Üniversitesi (ODTÜ)gibi birçok üniversite atık yönetimi ile ilgili komisyon kurup atıkların kaynağında ayrı toplanması ile ilgili çalışmalara başlamıştır (Anonim, 2019 a,b,c,d).

Yaşam döngü analizi entegre atık yönetiminde yaygın olarak kullanılan bir analiz olup atık arıtma yöntemlerinin ve bertaraf etme teknolojilerinin çevresel etkilerini hesaplamaktadır. Literatür incelendiğinde, farklı ülkeler ve şehirlerin kentsel atıklarının çevresel etkilerini hesaplayan birçok çalışma varken daha spesifik atık türü olan ambalaj atıkların geri dönüşümü için yürütülen araştırmalar da literatürde yer almaktadır (Herva ve ark., 2014; Özeler ve ark., 2006; Banar ve ark., 2009). Ancak üniversitelerden kaynaklı atık türleri için yaşam döngüsü analizi üzerine çalışmalar sınırlıdır. Her ne kadar üniversite atıklarının sıfır atık anlayışı ile yönetimi için birçok çalışma olmakla birlikte, üniversite atıklarının oluşturacağı çevresel etkiler hakkında bilgi yetersizdir. Bu bilgi eksikliğini gidermek için, Sakarya Üniversitesi Mühendislik Fakültesinde oluşan ambalaj atıkları çalışma alanı seçilerek, ambalaj atıklarının ayrı toplanması ve geri dönüşümü sonucu oluşacak çevresel etkiler belirlenmiştir. Ambalaj atıklarının geri dönüşümü yerine düzenli depolanması halinde çevresel etkilerin nasıl değişeceği ise karşılaştırılmalı analiz ile hesaplanmıştır. 


\section{Materyal ve Yöntem}

\section{1. Çalışma Alanı: Sakarya Üniversitesi Mühendislik Fakültesi}

1970 yılında Sakarya Mühendislik ve Mimarlık Yüksekokulu ile açılan Sakarya Üniversitesi, 1992 yılında 3837 sayılı kanun ile Sakarya Üniversitesi olarak eğitim ve öğretime başlamış olup, Mühendislik Fakültesi 296 adet akademik personel ve 8 adet mühendislik bölümü ile üniversitenin en büyük fakültelerinden biridir. Mühendislik Fakültesi, 8 adet binası ile $215.228 \mathrm{~m}^{2}$ alana sahip kampüste $39.050 \mathrm{~m}^{2}$ alanı kaplamaktadır. Çevre, İnşaat, Elektronik, Gıda, Endüstri, Jeofizik, Makine, Metalürji ve Malzeme Mühendisliği Bölümlerini içeren Fakültede 200 adet ofis, 82 adet derslik, 55 adet laboratuvar bulunmaktadır (Anonim, 2019 e).

\subsection{Mühendislik Fakültesinde Mevcut Ambalaj Atıkları Yönetimi}

Mühendislik Fakültesinde ambalaj atıklarının çeşitlerini ve miktarlarını belirlemek için tüm bina dersliklerinde mevcut durum tespiti yapılmıştır (Çizelge 2.1). Mevcut durum tespiti için hazırlanan çizelge binalar, bina sorumluları, binalardaki çöp kutuları, atık türleri ve atık yönetimi hakkında bilgileri içerecek şekilde 5 bölümden oluşmakta olup, çizelgenin çöp kutuları ile ilgili kısmına ilişkin bir örneği aşağıda gösterilmektedir (Güneralp ve ark.,2017). Mühendislik fakültesinden muhtemel çıkan karışık ambalaj miktarı yıllık 131 ton olarak hesaplanmış olup, \% 51 kağıt, \% 33 plastik, \% 11 cam ve \% 5 metal sırası ile çıkan ambalaj atık türüdür.

Çizelge 2.1. Mevcut Durum Tespit Çalışması

\begin{tabular}{|c|c|c|c|}
\hline \multicolumn{4}{|c|}{ ÇÖP KUTULARI HAKKINDA BİLGİ } \\
\hline \multicolumn{2}{|c|}{$\begin{array}{l}\text { HER KAT İÇİN BULUNDUĞU YERE GÖRE } \\
\text { (oda, labrotuvar,sinıf, koridor vb.) ÇÖP KU- } \\
\text { TUSU SAYISI, YAPILDIĞI MALZEME (me- } \\
\text { tal, plastik, kağıt vb.) ÇÖP KUTUSU HACMİ } \\
\text { (5L,10L,15L vb) NOT: GERİ DÖNÜŞÜM KU- } \\
\text { TULARI HARIÇ OLACAK VE SADECE Bİ- } \\
\text { NA İÇ MEKANI KAPSAYACAK }\end{array}$} & \multirow[t]{3}{*}{$\begin{array}{l}\text { HER KATTA GERİ } \\
\text { DÖNÜŞÜM KUTU- } \\
\text { SU SAYISI, TÜRÜ, } \\
\text { HACMI, YERİ VE } \\
\text { TOPLANAN ATIK } \\
\text { TÜRÜ }\end{array}$} & \multirow[t]{3}{*}{$\begin{array}{c}\text { BİNA DIŞ MEKAN } \\
\text { ÇÖP KUTUSU SAYI- } \\
\text { SI, TÜRÜ, MALZE- } \\
\text { MESİ VE HACMİ }\end{array}$} \\
\hline KORİDOR & DİĞER İÇ MEKAN & & \\
\hline $\begin{array}{l}\text { SAYI, MALZEME, } \\
\text { HACIM VE TOP- } \\
\text { LANAN ATIK TÜRÜ }\end{array}$ & $\begin{array}{l}\text { YERİ, SAYISI, MAL- } \\
\text { ZEMESI, HACMİ }\end{array}$ & & \\
\hline $\begin{array}{c}3 \text { adet, plastik, } 50 \mathrm{~L}, \\
\text { karışık atık }\end{array}$ & $\begin{array}{l}7 \text { adet } 10 \text { L plastik çöp } \\
\text { kutusu }\end{array}$ & & $\begin{array}{l}2 \text { adet } 25 \text { L krom çöp } \\
1 \text { adet } 50 \text { L plastik çöp }\end{array}$ \\
\hline $\begin{array}{c}3 \text { adet } 50 \text { L karış1k } \\
\text { atık için }\end{array}$ & $\begin{array}{l}5 \text { adet } 10 \mathrm{~L} \text { plastik çöp } \\
\text { kutusu }\end{array}$ & & \\
\hline $\begin{array}{l}2 \text { adet } 50 \mathrm{~L} \text { plastik } \\
\text { karış1k atık için }\end{array}$ & $\begin{array}{l}22 \text { adet } 10 \mathrm{~L} \text { plastik } \\
\text { çöp kutusu }\end{array}$ & $\begin{array}{c}1 \text { adet } 50 \text { L geri dö- } \\
\text { nüşüm kutusu }\end{array}$ & \\
\hline
\end{tabular}

Mühendislik fakültesinden toplanan ambalaj atıklarını Ambalaj Atıkları Kontrol Yönetmeliği gereğince, Sakarya Üniversitesi Serdivan ilçesi sınırlarında bulunduğu için belediyenin anlaşmalı olduğu geri dönüşüm tesisi, karışık toplanan kentsel atıkları ise Serdivan Belediyesi bertaraf etmektedir. Mühendislik fakültesinde oluşan cam, metal, kağıt ve karton, plastik ambalaj atıkların ayrı toplanması için üniversitenin anlaşmalı olduğu geri dönüşüm tesisi tarafından bırakılan karton çöp kutuları bulunmaktadır (Şekil 2.1).

Geri dönüşüm tesisine ait kutulardaki ayrı toplanmış ambalaj atıkları üniversitenin geçici depolama sahasında depolanmakta ve haftada 3 kere geri dönüşüm tesisi tarafından alınmaktadır. Mühendislik fakültesinde oluşan karışık atıklar gri plastik çöp kutularına atılmakta ve 
bunlar her gün fakülte çalışanları tarafından üniversitenin geçici depolama sahasına sevk edilmektedir. Geçici depolama alanından atıklar belirli periyotlarla alınmakta ve üniversiteye $11 \mathrm{~km}$ uzaklıkta bulunan düzenli depolama sahasında bertaraf edilmektedir.

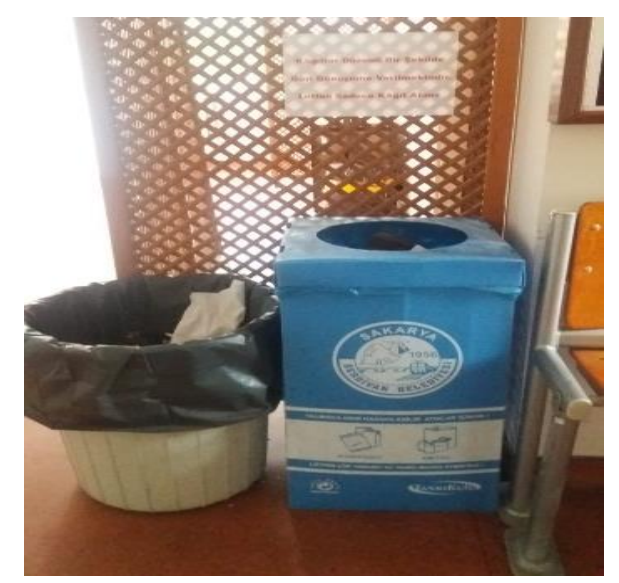

Şekil 2.1. Karışık evsel atık ve ambalaj atığı toplama kutuları

\subsection{Yaşam Döngüsü Analizi}

Mühendislik Fakültesinin yıl boyunca oluşan ambalaj atıkları (kâğıt-karton, plastik, cam ve metal) çalışmanın fonksiyonel birimini oluşturmakta olup, sistem sınırları karışık ambalaj atıklarının toplanması, taşınması, atık ayırma ve geri dönüştürme tesisinde ayrılması, kâğıtkartonun preslenip, metal ve camın preslenmeden geri dönüşüm firmalarına satılması, plastik atıkların kırılıp, granül haline getirildikten sonra plastik üreticilerine satılması, geri kalan artıkların ve geri dönüştürülemeyen malzemelerin yakma tesisinde bertarafını içermektedir (Şekil 2.2). Hâlihazırda Mühendislik Fakültesinde uygulan ambalaj atığı yönetimine ek olarak, ambalaj atıklarının geri dönüşüm tesisi yerine direk düzenli depolamaya gönderilme hipotezi halinde çevresel etkilerin ne olabileceği de çalışmanın kapsamı içerisindedir. Ambalaj atıklarının geri dönüşüm tesisinde işleme tabi tutulması ve burada oluşan firenin yakma tesisinde bertarafi ise Alternatif -1'i (A1), ambalaj atıklarının direkt düzenli depolamaya gitmesi sonucu oluşan çevresel etkiler Alternatif-2 (A2), oluşturmaktadır. Bu çalışmada ayrıca, Alternatif 1 (uygulanan yönetim) ve Alternatif 2 (kurgulanan hipotez) karşılaştırılarak çevresel etkilerin nasıl değişebileceği belirlenmiştir. 


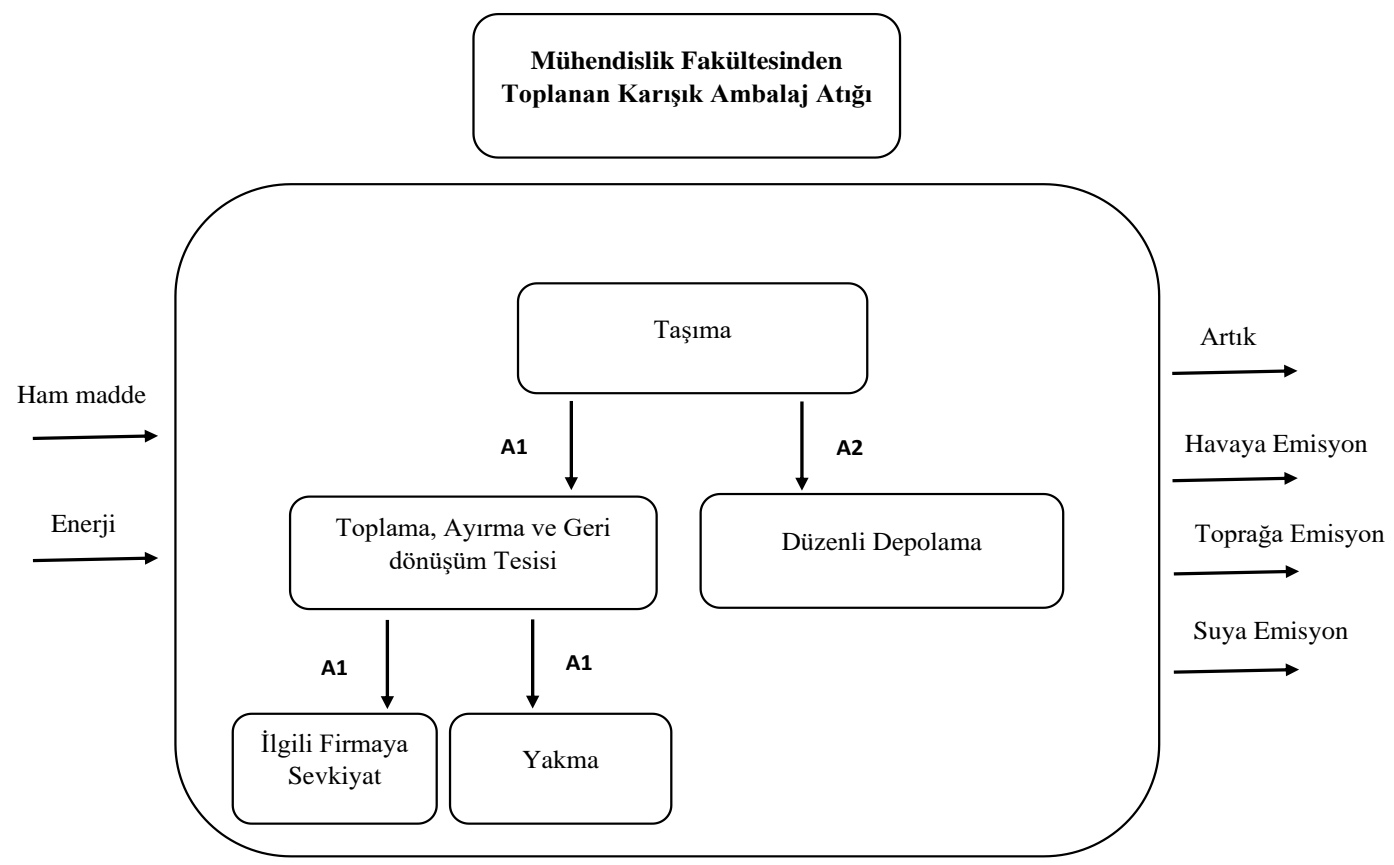

Şekil 2.2. Sistem sınırları

Simapro 8,4 programı kullanılarak hesaplanan yaşam döngüsü analizinde, atık karakterizasyonu ve anket çalışması, il çevre durum raporu, ecoinvent veri tabanı ve geri dönüşüm ve düzenli depolama tesis bilgileri döküm verisi olarak kullanılmıştır. Şekil 2.3'te geri dönüşüm tesisinin iş akım şeması gözükmektedir. Bu iş akım şemasına göre, üniversiteden karışık ambalaj atıklarını toplayan araç geri dönüşüm tesisine geldiğinde, atıklar ayırma bandı üzerine boşaltılmakta ve kâğıt ile plastik atıklar birbirinden el ile ayrılmaktadır. Kâğıt ve plastik harici ambalaj atığı olmayan atıklar ise fire olarak adlandırılmaktadır. Bu fireler Gebze'de bir çimento fabrikasına sevk edilmektedir. Kağıt atıklar tekrar bir konveyör bant aracılığıyla pres makinesine taşınmakta ve balyalar halinde depolanıp geri dönüşüm tesislerine sevk edilmektedir. Plastik atıklar ise cinslerine göre ayrılmakta (HDPE,PE,PP,LDPE, PS, ABS) ve kostikli su ile yıkanmaktadır. Bu işlem sonucu oluşan yıkama suyu arıtma tesisine gitmekte ve arıtma çamuru haline getirilip $30 \mathrm{~km}$ uzaklıktaki lisanslı bir bertaraf tesisinde bertaraf edilmektedir. Y1kamadan sonra atıklar agromel makinesine girmekte ve hem kurutma hem de kırma işlemi gerçekleşmektedir. Agromelde kurutulup kırılmış plastik, granül makinesinde eritilip elekten geçmekte ve uzun iplik halindeki plastik, granül makinesi çıkışındaki dönen bıçaklar yardımıyla dairesel 0,4-0,5 cm boyutuna getirilip çuvallanmakta ve soğumaya bırakılmaktadır. Son işlem olarak ilgili alıcıya sevk edilmektedir. 


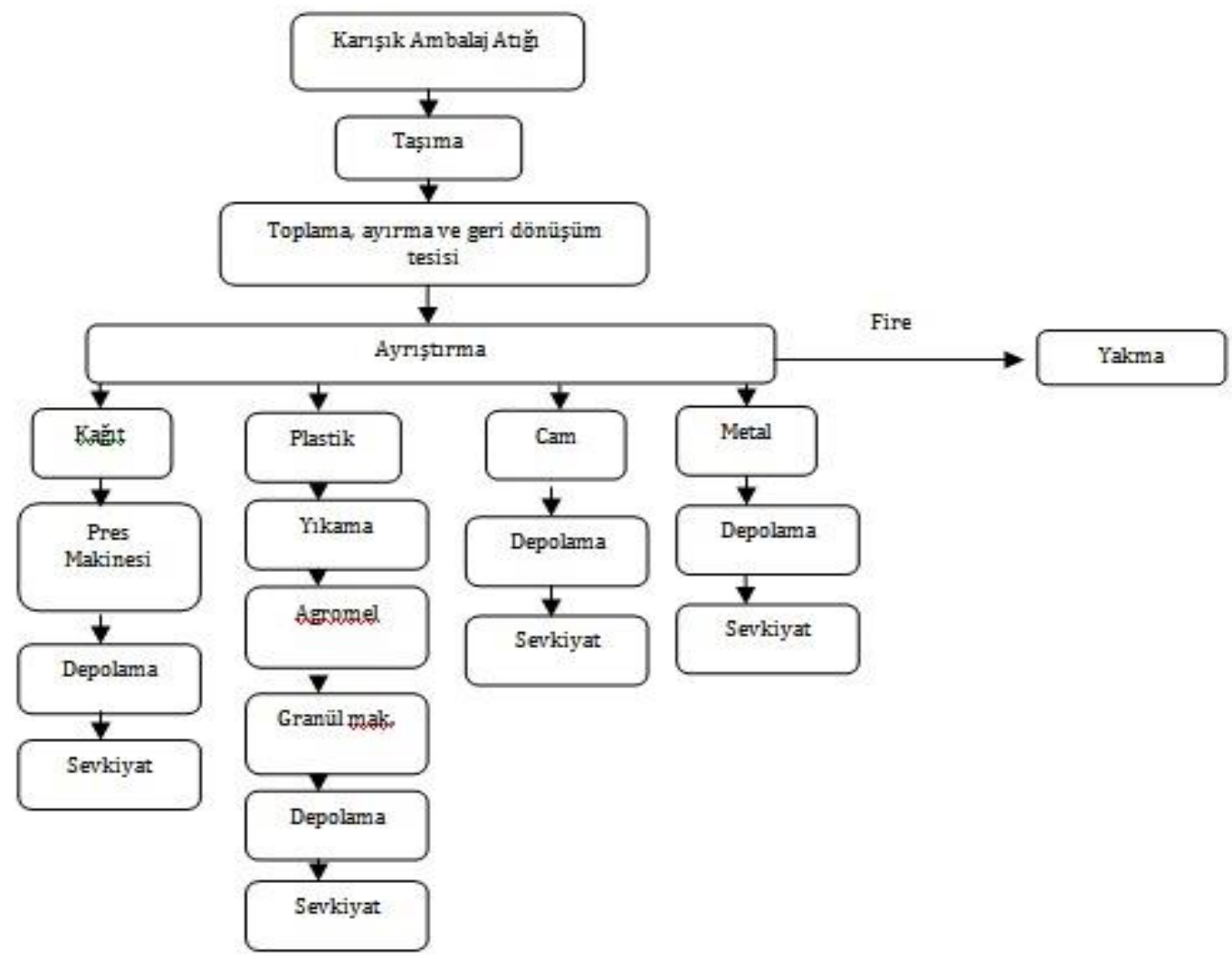

Şekil 2.3. Geri dönüşüm tesisi iş akış şeması

Ambalaj atıklarındaki plastik ambalajlar ikincil hammadde elde edilerek hem vahşi depolanan atık miktarında azaltıma gidilmekte hem de tekrar kullanım sağlanmış olunmakta ve bu atıklardan ekonomik gelir elde edilmektedir. Bu geri dönüşüm işlemi sonucunda Çizelge 2.2'de ayrıntıları gösterildiği üzere plastiklerin yıkanması için kostik ve su sarfiyatı, kağıt atıkların balyalanması için kullanılan pres makinesinden, plastik atıkların granül haline gelmesi için kullanılan agromel ve granül makinelerinden oluşan elektrik sarfiyatı oluşmaktadır. Programda veri girişi yapılırken elektrik sarfiyatları için "Electricity, medium voltage $\{T R\}$ market for/conseq S" kağıt ve granülün taşınması için "Transport, lorry 7,5-16 t, Euro5/RER S" cam ve metalin taşınması için "Transport, municipal waste collection, lorry $21 \mathrm{t} / \mathrm{CH} \mathrm{S"} \mathrm{su} \mathrm{tüketi-}$ minde "Water, unspecified natural origin, TR" plastiğin granül haline getirirken kullanılan $\mathrm{NaOH}$ için ise "Sodium Hydroxide, without water, in \%50 solution state $\{\mathrm{GLO}\} \mid \mathrm{S}$ " seçilmiş ve hesaplama yapılmaktadır.

Çizelge 2.2. Tesislerde kullanılan ekipmanların tükettiği hammadde ve enerji

\begin{tabular}{|l|l|l|}
\hline Atık cinsi & \multicolumn{1}{|c|}{ İşlem } & $\begin{array}{l}\text { Tüketilen kaynak } \\
\text { ve birimi }\end{array}$ \\
\hline & Agromel Ünitesi Makineleri & $555,2 \mathrm{kw} /$ ton atık \\
\hline Ambalaj atıkları & Granül Ünitesi Makineleri & $175 \mathrm{kw} /$ ton atık \\
\hline & Kağıt presleme & $5 \mathrm{kw} / \mathrm{ton}$ \\
\hline & Kostik & $5 \mathrm{lt} /$ ton \\
\hline & $\mathrm{Su}$ & $0.025 \mathrm{~m}^{3} /$ ton \\
\hline
\end{tabular}


$\mathrm{Bu}$ çalışmada mevcut ambalaj atık yönetiminde ambalaj atıklarının geri dönüştürülemeyen kısımları ve karışık toplanan atıklar direk düzenli depolamaya gönderilmesi söz konusudur. Üniversite Sakarya'da bulunduğundan, Sakarya iline ait düzenli depolama verileri kullanılmıştır. 2017 yılı ton atık başına normalize edilmiş baca gazı ve sızıntı suyu analizleri Çizelge 2.3 'de verilmiştir.

Çizelge 2.3. Sakarya düzenli depolama emisyonları

\begin{tabular}{|l|l|l|l|}
\hline \multicolumn{2}{|l|}{ Sizınt1 Suyu Emisyonu } & \multicolumn{2}{c|}{ Gaz Emisyonlar1 } \\
\hline Kompozisyon & Birim(g/ton) & Kompozisyon & Birim (g/ton) \\
\hline KOİ & 347,61 & $\mathrm{CH}_{4}$ & 0,0493 \\
\hline $\mathrm{BOI}$ & 192,62 & $\mathrm{O}_{2}$ & 0,1084 \\
\hline $\mathrm{TKN}$ & 0,544 & $\mathrm{CO}_{2}$ & 0,112 \\
\hline $\mathrm{TP}$ & 0,127 & $\mathrm{H}_{2}$ & 0,000016 \\
\hline $\mathrm{TCr}$ & 0,061 & $\mathrm{H}_{2} \mathrm{~S}$ & 0,0009 \\
\hline $\mathrm{Cr}$ & 0,255 & & \\
\hline $\mathrm{Pb}^{+6}$ & 0,0644 & & \\
\hline $\mathrm{Fe}^{+2}$ & 0,342 & & \\
\hline $\mathrm{Fe}^{-}$ & 0,342 & & \\
\hline $\mathrm{Cu}$ & 0,375 & & \\
\hline $\mathrm{Zn}$ & 0,095 & & \\
\hline $\mathrm{pH}($ birimsiz) & 7,44 & & \\
\hline
\end{tabular}

\section{Bulgular ve Tartışma}

Çalışmada çevresel etkiler CML-IA hesaplama yöntemi ile hesaplanmış olup, yöntemin etki gruplarını küresel, bölgesel ve yerel etkileri gösteren 3 grupta toplayabiliriz. Bu etki gruplarının alt etki grupları ise abiyotik tükenme, abiyotik tükenme (fosil yakıtlar), küresel 1sınma, ozon tabakası tahribatı, insan toksisitesi, tatlı su ekotoksisitesi, deniz ekotoksisite, karasal ekotoksisite, fotokimyasal oksidasyon, asidifikasyon ve ötrofikasyondur. Mühendislik Fakültesinde oluşan ambalaj atıklarının geri dönüşümü (Alternatif 1) veya düzenli depolamada bertarafı (Alternatif 2) senaryoların her etki kategorisi için YDA karakterizasyon analizinin sonuçları Çizelge 3.1'te verilmiştir. Farklı yönetim alternatiflerinin kıyaslaması ise Şekil 3.1 ve 3.2'de gösterilmiştir.

Çizelge 3.1. Yaşam döngüsü analizi karakterizasyon analizi

\begin{tabular}{|c|c|c|}
\hline Etki Kategorisi & Alternatif 1 & Alternatif 2 \\
\hline & & 2,55 \\
\hline Abiyotik Tüketim (kgSb eq) & 7,14 & $7,26 \mathrm{E}-6$ \\
\hline Abiyotik Tüketim (MJ) (Fosil Yakitlar) & $2,42 \mathrm{E}-7$ & $5,49 \mathrm{E}-6$ \\
\hline Küresel Isınma (kg CO ${ }_{2}$ eq) & $3,68 \mathrm{E}-6$ & 0,282 \\
\hline Ozon Tabakas1 İncelmesi (kg CFC-11 & 0,555 & $1,13 \mathrm{E}-6$ \\
\hline eq) & & $9,92 \mathrm{E}-5$ \\
\hline İnsana Toksisitesi (kg1,4 DB eq) & $6,93 \mathrm{E}-5$ & $2,64 \mathrm{E}-9$ \\
\hline Tatl1 Su Ekotoksisitesi (kg 1,4 DB eq) & $3,12 \mathrm{E}-5$ & $1,89 \mathrm{E}-3$ \\
\hline Deniz Ekotoksisitesi (kg 1,4 DB eq) & $1,17 \mathrm{E}-9$ & 821 \\
\hline Karasal Ekotoksisite $(\mathrm{kg} 1,4 \mathrm{DB}$ eq) & $2,17 \mathrm{E}-3$ & $2,05 \mathrm{E}-4$ \\
\hline Fotokimyasal Oksidasyon $\mathrm{kg} \mathrm{C}_{2} \mathrm{H}_{4}$ eq) & 474 & $1,15 \mathrm{E}-4$ \\
\hline Asidifikasyon $\left(\mathrm{kg} \mathrm{SO}_{2} \mathrm{eq}\right)$ & $1,5 \mathrm{E}-4$ & \\
\hline Ötrofikasyon $\left(\mathrm{kg} \mathrm{PO}_{4} \mathrm{eq}\right)$ & $5,85 \mathrm{E}-3$ & \\
\hline
\end{tabular}


Karakterizasyon sonuçlarına baktığımızda, geri dönüşümün abiyotik tükenme, ozon tabakası tahribatı ve karasal ekotoksisite parametrelerinde yüksek olduğu gözlenmektedir. Sonuçları normalize ettiğimizde ise ambalaj atıklarının düzenli depolamada bertarafın daha fazla olumsuz çevresel etkileri olduğu bulunmuş olup, etki parametreleri içerisinde deniz suyu ekotoksitesinin en büyük etki parametresi olduğu görülmüştür. Literatüre göre deniz suyu ekotoksisitesi depolamadan kaynaklı sızıntı suyunda oluşan nikel, bakır, berilyum, gibi birincil kirleticilerden ve elektrik kullanımından kaynaklı vanadyum, baryum gibi kirleticilerden kaynaklanmaktadır. Alternatif-1 de kağıt atıkların balyalanması ve plastik atıkların granül haline getirilmesinde elektrikli ekipman kullanımından kaynaklanmaktadır. Alternatif-2 de ise yalnızca düzenli depolama yapıldığından değer yüksek görülmektedir. İkinci en büyük etkiye sahip parametre tatlı su ekotoksisitesisi ise elektrik kullanımı ve $\mathrm{NaOH}$ kimyasalı kullanımından kaynaklandığ 1 program verilerince belirlemiştir.

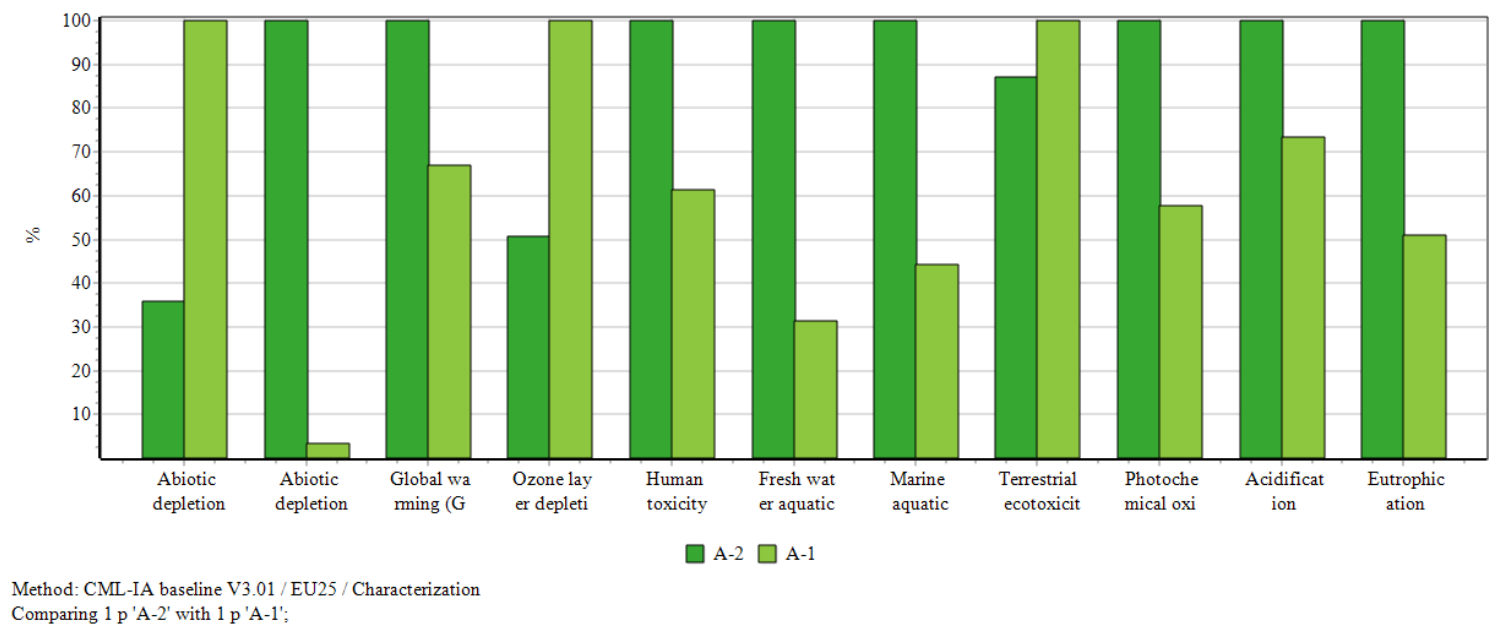

Şekil 3.1. CLM-IA Baseline metodolojisi ile kıyaslama grafiği-Karakterizasyon

Temel olarak atıkların toplanması ve taşınması sırasında yakıt tüketiminden kaynaklanan abiyotik tüketimdir. Alternatif-1'de ambalaj atıkları üniversitenin geçici depolama sahasından alınıp alıcıya ve bertaraf tesislerine ulaştırılmasına kadar $512 \mathrm{~km}$ 'lik taşıma gerçekleşmekte iken, Alternatif-2'de yalnızca geçici depolama sahasından alınan atık $11 \mathrm{~km}$ uzaklıktaki düzenli depolama sahasına taşınmaktadır. Mesafe arttıkça yakıt tüketimi arttığından abiyotik tüketim alternatif 1 için daha yüksek sonuç vermektedir. Düzenli depolama sonucu oluşan gaz emisyonundan ve yakıt tüketiminden kaynaklanan $\mathrm{CO}_{2}$ gibi sera gazları sonucu ortaya çıkan küresel ısınma parametresinin Alternatif-1'de oluşma sebebi taşımadan kaynaklı yakıt tüketimiyken, Alternatif-2'de oluşma sebebi düzenli depolama sahasında oluşan Çizelge 2.3 de gösterilmiş olan gaz emisyonlarıdır. Fotokimyasal Oksidasyon parametresinin kaynakları $\mathrm{CO}, \mathrm{NO}, \mathrm{SO}_{2}, \mathrm{NH}_{3}$ gibi gazlar ve yakıt tüketimidir. Asidifikasyon parametresi de yakıt tüketiminden kaynaklanmaktadır (Erses Yay, 2015; Pelesaraei ve ark., 2017; Cherubini ve ark., 2009; Geyhan ve ark., ). 


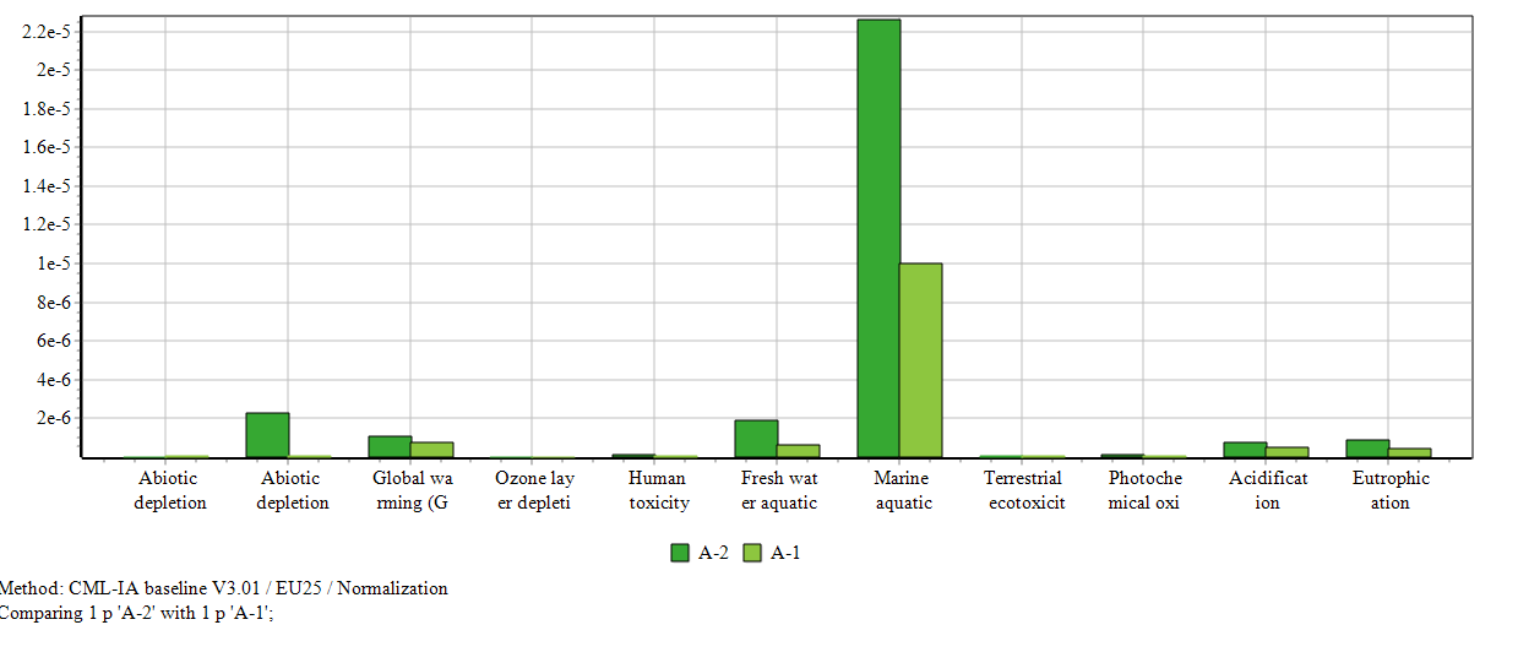

Şekil 3.2. CLM-IA Baseline metodolojisi ile kıyaslama grafiği-Normalizasyon

Kısacası taşımadan kaynaklı olarak oluşan emisyon, düzenli depolamadan kaynaklı olarak oluşan gaz emisyonları ve program veri tabanından seçmiş olduğumuz yakma prosesinden kaynaklı oluşan gaz emisyonları abiyotik tüketim, küresel 1sınma, fotokimyasal oksidasyon ve asidifikasyon parametrelerine; depolama sızıntı suyu ve geri dönüşümde kullanılan yıkama suyun deniz suyu ekotoksisitesi, tatlı su ekotoksisitesi ve ötrifikasyon parametrelerine; elektrik tüketiminden kaynaklı olarak deniz suyu ekotoksisitesi parametresine etki etmektedir.

$\mathrm{Bu}$ çalışma sonuçların güvenirliğini ve hassasiyetini kontrol etmek için duyarlılık analizi yapılmıştır. Duyarlılık analizi etki değerlendirme yöntemi değiştirilerek gerçekleştirilmiştir. Mevcut çalışmada CML-IA yöntemi kullanılırken, duyarlılık analizi için IMPACT 2002 kullanılmıştır. Şekil 3.3 ve 3.4, farklı etki yöntemi kullanarak yapılan duyarlılık analizi sonuçlarını göstermektedir. Şekiller incelendiğinde, aynı veriler ile IMPACT 2002 metodolojisi seçildiğinde de yalnızca düzenli depolama sahasına gömülmesinin ambalaj atıklarının geri dönüştürülmesi ve burada oluşan firelerin yakma tesisinde bertarafina göre etki parametrelerindeki değerlerin çok daha yüksek olduğu anlaşılmıştır. Her iki metodolojide de geri dönüşümün çevresel etkilerinin daha düşük olduğu görülmüştür.

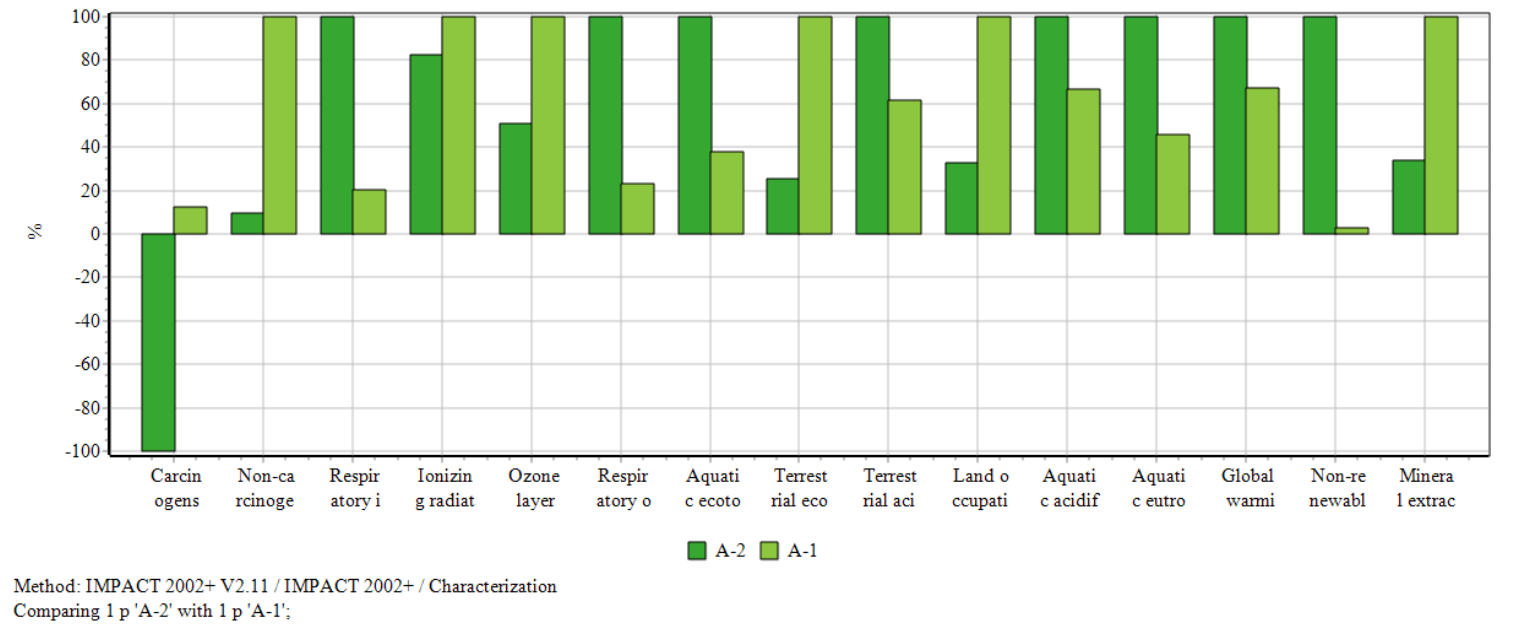

Şekil 3.3. Impact metodolojisi ile kıyaslama grafiği Karakterizasyon 


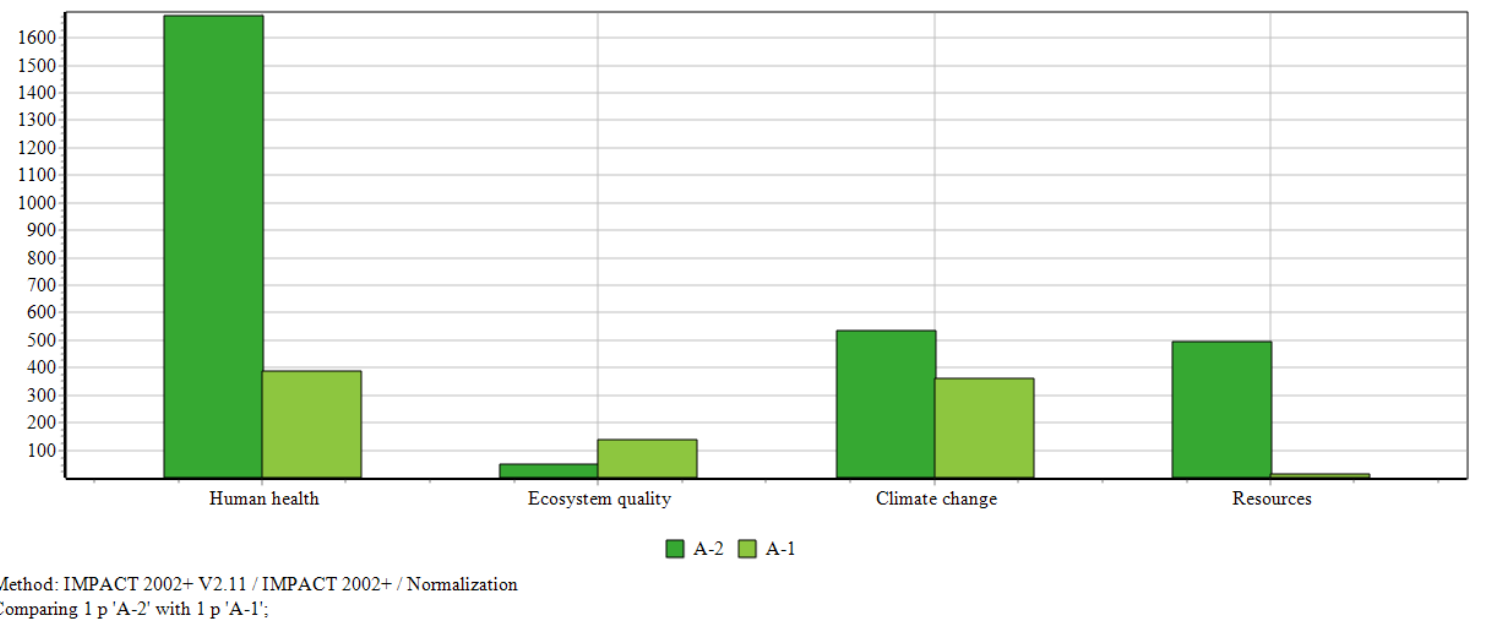

Şekil 3.4. Impact metodolojisi ile kıyaslama grafiği Normalizasyon

\section{Sonuç}

Yaşam döngüsü analizinden elde edilen verilere göre, mühendislik fakültesinde oluşacak ambalaj atıklarının ayrı toplanması ve geri dönüştürülmesi, düzenli depoda bertaraf edilmesine göre olumsuz çevresel etkileri azaltacağ 1 ve düzenli depolamaya göndermenin kaynakların israfına yol açacağı sonucuna varılmıştır. Çalışmada farklı etki değerlendirmeleri kullanılsa bile sonuçların çevresel etkiler kategorilerinde benzerlik göstererek, duyarlılık analizi sonuçlarının güvenilir olduğunu göstermiştir. 


\section{Kaynakça}

Anonim 2017. Ambalaj Atıklarının Kontrolü Yönetmeliği, 30283, 27.12.2017.

Anonim 2019a. Çevre ve Şehircilik Bakanlığı. http://sifiratik.gov.tr/ (26.04.2019)

Anonim 2019b. İstanbul Teknik Üniversitesi. http://www.yesilkampus.itu.edu.tr/ (26.04.2019)

Anonim 2019c. Orta Doğu Teknik Üniversitesi. https://ncc.metu.edu.tr/tr/yesil-kampus $(26.04 .2019)$

Anonim 2019d. Boğaziçi Üniversitesi. http://www.boun.edu.tr/tr_TR/Content/ Kampus_Yasami /Kampus YesilKampus (26.04.2019)

Anonim 2019e. Sakarya Üniversitesi. http://www.sakarya.edu.tr/tr (26.04.2019)

Banar M., Cokaygil Z., Ozkan A., 2009. Life Cycle Assessment Of Solid Waste Management Options For Eskişehir, Turkey. Waste Management 29:54-62.

Cherubini F., Bargigli S., UlgiatiS., 2009. Life Cycle Assessment (LCA) of Waste Management Strategies: Landfilling, Sorting Plant and Incineration Energy, 34:2116-2123.

Erses Yay A.S., 2015. Application of life cycle assessment (LCA) for municipal solid waste management: a case study of Sakarya. Journal of Cleaner Production, 94: 284-293.

Geyhan Y.E., Çiftçi Y.G., Çiftçioğlu A.G.A., Kadirgan M.A.N., 2016. Environmental Analysis of Different Packaging Waste Collection Systems For Istanbul-Turkey Case Study, Resources Conservation And Recycling, 107:27-37.

Güneralp S.,Aydıner F.,Tok M., Ayaz M., Babacan M., Akbaş B., Değirmenci S., Uzun S., Kıvan B., Saban E., 2017 Sakarya Üniversitesi Atık Yönetim Planı, Lisans Tezi, Sakarya Üniversitesi, Sakarya, Türkiye.

Herva M., Neto B., Roca E., 2014. Environmental Assessment of The Integrated Municipal Solid Waste Management System in Porto (Portugal). Journal Of Cleaner Production, 70:183-193.

Pelesaraei N.A., Bayat R., Bandbafha H.H., Afrasyabi H., Chau K., 2017. Modeling of Energy Consumption and Environmental Life Cycle Assessment for Incineration and 
Landfill Systems of Municipal Solid Waste Management-A Case Study in Tehran Metropolis of Iran. Journal Of Cleaner Production, 148:427-440.

Özeler D.,Yetis Ü., Demirer G.N., 2006. Life Cycle Assessment of Municipal Solid Waste Management Methods: Ankara Case Study. Environment International, 32:405-411. 